\title{
On Design of IoT-based Power Quality Oriented Grids for Industrial Sector
}

\author{
Nesma N. Gomaa ${ }^{1,2}$, Khaled Y. Youssef ${ }^{*}, 3$, Mohamed Abouelatta ${ }^{1}$ \\ ${ }^{1}$ Faculty of Engineering, Electronics and Electrical Communication, Ain Shams University (ASU), Cairo, 11757, Egypt \\ ${ }^{2}$ Faculty of Engineering, Electronics and Electrical Communications, October University Modern Sciences and Arts (MSA), Cairo, \\ 11757, Egypt
}

${ }^{3}$ Faculty of Navigation Science and Space Technology, Beni-Suef University (BSU), Beni Suef, 62511, Egypt

\section{A R T I C LE IN F O}

Article history:

Received: 16 September, 2020

Accepted: 16 December, 2020

Online: 25 December, 2020

Keywords:

Energy Management System

Internet of Things (IoT)

Power system

Power Factor

Harmonics

Power quality

\begin{abstract}
A B S T R A C T
Manufacturing industry is facing several challenges in power quality and energy consumptions that play a significant role in the cost of goods sold in addition to the operational efficiency of manufacturing plants. The current techniques are not enough to manage the manufacturing processes from power perspectives as it is focusing only on the monitoring of the power grids using smart meters connected to SCADA systems. In this paper, a novel technique is proposed that is based on energy-aware manufacturing process control model using internet of things technology. The model is applied on cabling industry use case in addition to implementation of a MATLAB model for this purpose whereas the IoT physical layer is collecting, analyzing and communicating the electric power parameters correlated with the manufacturing process parameters received from PLC IoT nodes. Accordingly, the effective power quality is enhanced using manufacturing process control rather than additional correction nodes in traditional techniques. On applying the model on cabling use case, the Total Harmonic Distortion (THD-current) is improved 10 times to be $3.1 \%$ against $31.4 \%$ and the power factor is improved by $33 \%$ from 0.7 to 0.93 without additional correction nodes.
\end{abstract}

\section{Introduction}

This paper is an extension of work originally presented in 15 th International Computer Engineering Conference (ICENCO) [1]. Power Quality ( PQ) has recently become a very important topic because of its effect on energy producers, equipment's, manufacturers and consumers. There are so many industries nowadays that produce and use high technology for production thus high quality and high reliability are needed for these supplying strength [2]. The advantages of gathering real time monitoring is to develop the perception of awareness for power quality in factories.

Despite these circumstances, the executions of energy quality steps in improving energy efficiency have not yet satisfied expectations. The reason for the deficits in energy efficiency realization include lack of time and clarity on energy consumption [3]. The widespread use of non-linear loads leads to a huge distortion of voltage and especially current waveforms that affect

*Corresponding Author: Khaled Y. Youssef, khalid_youssif@yahoo.com any power electronic system [4]. In power systems, harmonic distortion and power factor disturbance increase on daily basis due to an increase in the use of nonlinear loads such as system resonances, voltage distortion, interference with communications networks, transformers overloading, a negative impact on energy metering and a decrease in the overall system efficiency. Thus, these two factors are set to be a serious problem in terms of power quality and this may affect other pieces of equipment connected to a particular system. The optimal performance between increasing in energy demand without severe increases in energy costs come to be our challenge now days. Hence, according to IEEE and International Electro-technical Commission (IEC) standards, industries must devote a greater attention to keeping harmonics and Power Factor (PF) within permissible limits $[5,6]$. Furthermore, (IoT) could have significant contribution on energy management, hence several (IoT) applications to reduce the energy consumption have been developed [7, 8].

Power quality (PQ) monitoring methods that are recently produced have the capability to calculate and store data 
automatically with a high sampling rate. Significant quantities of measured data, such as current signals, voltage signals, total harmonic distortion, and power factor, can be obtained by monitoring devices. Yet, they do not identify distortions automatically, and involve off-line analysis of the data recorded. Consequently, in order to identify the type of end-use equipment, harmonic variations, and power factor detection a real time technique study is provided in this paper to develop the perception of awareness for power quality in factories and examine the impact of energy efficiency in industries. In today's power systems connected to nonlinear loads, voltage and current waveform distortion are more prevalent. The prevalence and interaction of loads of this kind with the power supply system increases the need to use power monitoring equipment to assess the quality of electric power. This paper proposes a new architecture which makes use of real-time data to ensure prediction of machine failure, using power quality data and ways to improve the energy efficient process. The algorithm proposed can be used for automated correction of industrial energy profile using Internet of Things (IoT) technology.

\section{Literature review}

Systematic approaches to eliminate the consumption of energy has been studied. Hence in order to explain the significance of problems with power quality, a detailed representation of any nonlinear system may be needed in the case of weak systems as interactions may occur between harmonics of different orders in such systems that are not predicted by linear time invariant models. Thus to identify and evaluate energy quality indices for various categories of electricity users, a fuzzy logic-based approach is suggested in [9]. Low energy quality is a serious concern for domestic, commercial and industrial users, in [10] issues of power quality in electrical systems is illustrated briefly.

Harmonics in electricity networks have recently gained even more attention from the power industry as a key cause of PQ problems, in [11], the total harmonic and unbalance distortion is well-defined to help factories to reduce harmonic distortion. In [12], an index is determined to represent the thermal effects on three phase induction motors as a result of harmonic distortions. Researchers in $[13,14]$ illustrate other methods of PQ disturbances such as inter harmonics and voltage fluctuations. Furthermore, a Harmonic Trap Filter in conjunction with a line reactor designed and implemented by [15], using Simulink to demonstrate the principle of harmonic analysis in a three-phase system.

Additionally, the dramatic increase of electricity each year take the initiative on the aspect of energy efficiency in order to address the environmental issues. One of these aspects is the power factor correction. In [16], it is studied the importance of power factor which reflects how much the industries or organizations will consume the electricity efficiently. In [17], the authors investigate a system to carry out the effect of power factor on inductive loads using capacitor bank. Moreover, a system using a thyristor switching capacitor was proposed by [18], which helped to improve the quality of power and regulate the reactive power under the regularization of power factor.

Decreasing energy consumption is important for increasing productivity thus the relationship between electricity and economic growth is vital .To conserve energy and enhance its efficiency, smart grids (SG) were developed to do that [19]. John S. In [20], it is highlighted and clarified the different demand response (DR) programs. A number of DR-based programs are offered to organization managers and consumers, in general, where they choose which program they want to follow in order to decrease the overall energy consumption. Likewise, as energy saving has been one of the critical problems in designing electronic devices, Smart home appliance control system was developed in the IoT environment, a smart control system based on the technologies of internet of things has been proposed in [21].

\section{Architecture for power quality management using IoT technology}

In this paper a new architecture is proposed to increase the levels of power efficiency in industries. A smart energy management technique is illustrated in Figure 1. Using this block diagram will help factories to reduce their energy consumption. This architecture depends on tracking different loads in the downstream zone.

The architecture shown in Figure 1 is focused on monitoring the different loads attached in a Sensor Area Network (SAN), for the purpose of automated real-time monitoring of transient behaviour and accordingly the detection of anomalies related to power quality issues as voltage dwells, low power factor, and high order harmonics, that might happen as a result of grid's load nonlinear behaviour. Most of this phenomenon is currently detected by capture of a measurement sample from the sub-system under test and that is usually reactive rather than proactive.

The concept emphasized by the study is about converting the grid system into an autonomous grid that has the ability to auto detect the phenomenon using a transit-time domain analysis and thus paves the way for artificial intelligence techniques on board to automatically detect the abnormal phenomena even on odd occurrence based on the intra-load communication, source-load communication and load on board processing. The concept also states the edge of machine to machine communications that is the core base of the well-known IoT technology.

According to Figure 1, the central processing server (CPS) is the node that is responsible for orchestration of the correction nodes on the correction plane according to the dynamicity of the load, and thus the CPS calculates and signals the configuration parameters to the corresponding correction nodes based on the measurements done by the IoT layer. The key difference between the existing techniques of correction and the proposed technique is mainly the holistic management of correction for the detected problem according to the multi-factor causal analysis.

One example is the power factor transient's detection that will be captured by IoT layer that is then escalated to CPS layer which in turn take the holistic decision to off -load the power factor capacitor bank and signal the synchronous power factor correction node to be in place in addition to active harmonic cancellation node in place of the passive one. The solution needs a level of intelligence as the classical capacitor bank response time to the change in loads will cause the failure of the classical technique. Moreover, the active cancellation will become effective due to the significant presence of several orders of harmonics rather than the 
classical passive filter mode. The edge of the IoT layer in this example is in the consolidated view for the potential sources of problem with the decision of act on the optimum solution of correction.

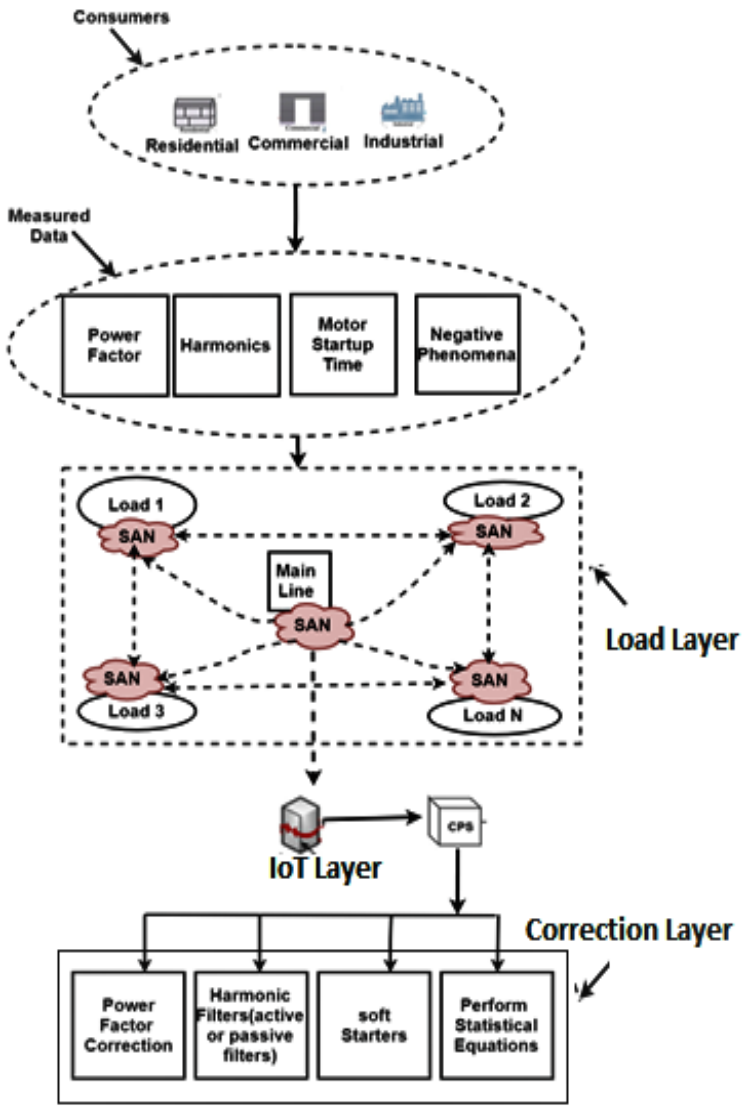

Figure 1: Schematic for the modules combining an intelligent energy management system in factories.

Illustrated in Figure 2 the concept of IoT smart grid which adds intelligence at each step by using online monitoring of transmission lines for disaster prevention and efficient use of power in order to decrease the overall energy consumption inspired by the factory. The three-layer architecture provides a high level framework through which different approaches might be implemented. The first layer consists of Machine drives, which are pumps, electric motors, and fans, account for about half of the manufacturing sector's delivered electricity, layer two is the IoT layer which consists of IoT beacon which are used as linking bridge that helps to provide total tracking and the last layer is named by correction plane layer in which the power factor correction bank and the harmonic filter exists.

The energy efficiency scheme is demonstrated by the flow chart in Figure 3, which begins by monitoring various production lines where each line has different load numbers, $\mathrm{X}$ is the order of each load, and $\mathrm{N}$ is the total number of loads. Two different parameters are evaluated on each load; power factor and harmonics. The CPS can detect if any of these parameters are not functioning effectively. A signal is sent to the CPS in the event of any errors. Where the problem can be overcome by the CPS,

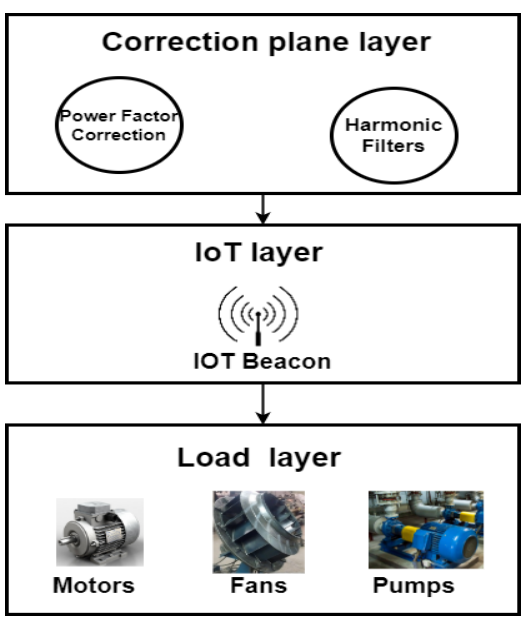

Figure 2: IoT architecture for smart grid.

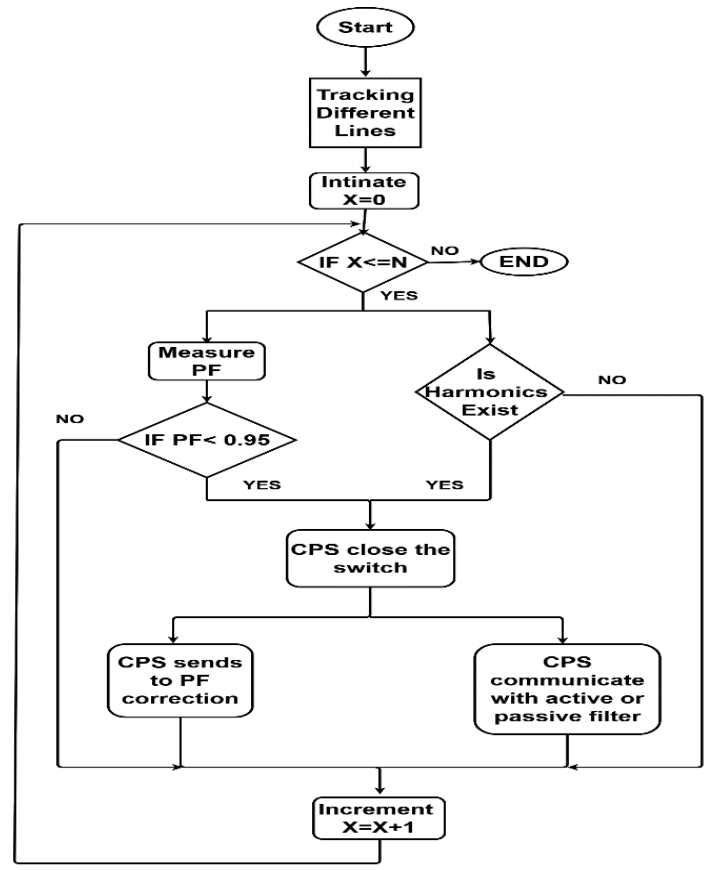

Figure 3: Flow Chart for energy saving analysis.

\section{Power Factor correction and Harmonics detection Matlab simulation model results and analysis}

A Matlab Model is designed to limit the voltage and current harmonics to be applicable with the IEC standards and to improve the power factor value. A Three-phase harmonic filters with power factor correction model for High-Voltage Direct Current (HVDC) is designed in Figure 4, using Matlab Simulink platform to reduce the voltage and current distortion in the power system. The model is designed using a frequency of $60 \mathrm{HZ}$ and a firing angle $\alpha=19^{\circ}$. One capacitor bank C1 of 150 Mvar designed by a "Thee-Phase Series RLC Load". Three types of different filters combination were also used including one $\mathrm{C}$-type high pass filter tuned to the 3rd F1 of 150 Mvar ,one doubled -tuned filter 11/13th F2 of 150 Mvar and one high pass filter tuned to the 24th F3 of 150 Mvar.

The model used a switch control device for reducing the load imbalance and improving the efficiency of data processing. This 
switch control is used to switch on or off when the CPS detect that the data received from the load is not achieving the threshold. The filter can be activated and deactivated using the breaker in the circuit. When the breaker (i.e. CPS) is closed, the filter is activated, the current and voltage will pass through the filter and will successively be filtered. Conversely when the breaker is opened the filter will be deactivated and will have no effect on the output waveforms of the system.

After running the developed Simulink model with different values of $\alpha$. A various responses are observed. The waveforms in Figure 5, 6 respectively illustrate that when the breaker is opened, the filter is deactivated, a highly distorted waveform was detected because of the nonlinear loads that can be existing in the system. Hence when the breaker is closed, the filter can remove the harmonics given the desired waveform which is free from distortion.

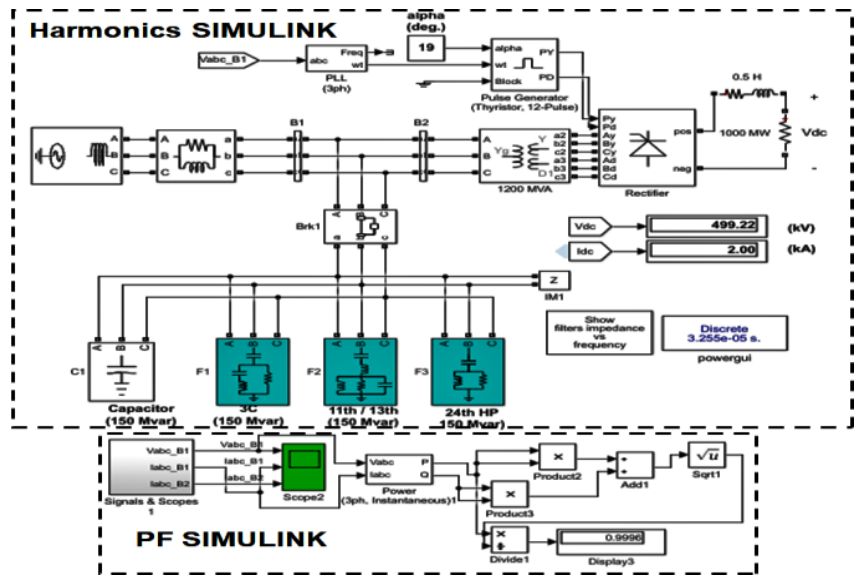

Figure 4: Three Phase Harmonic Filter with aid of PF correction (Simulink Design).
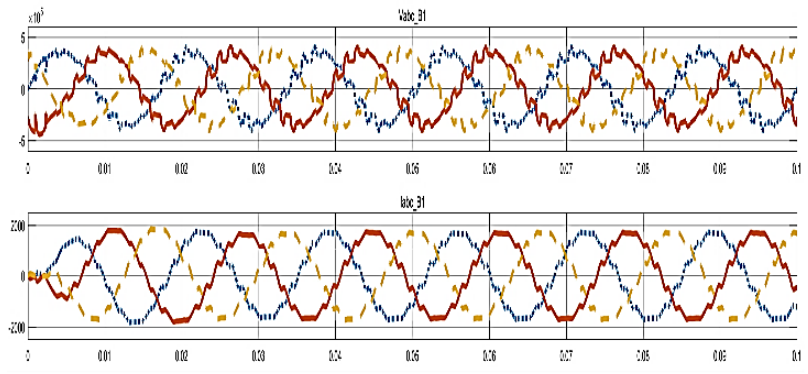

Figure 5: Output Waveforms when filter is disconnected.

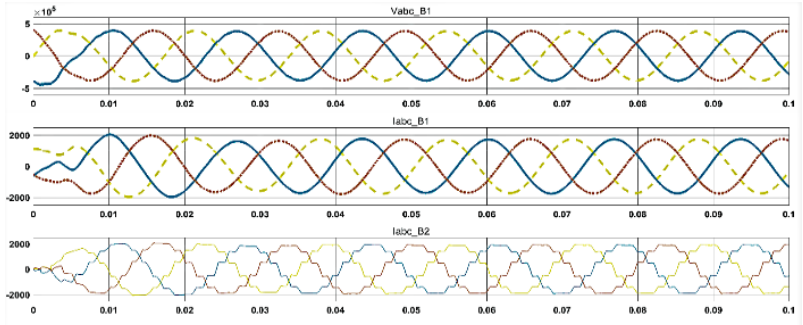

Figure 6: Output Waveforms when filter is connected.

Table 1 and table 2 illustrate that by using a suitable harmonic filter with the aid of a suitable capacitor value, we can control the flow of these fluctuations. From theses measureable results, it can be inferred that the system has worked successfully. As for www.astesj.com example, it is clear that with the assistance of the harmonic filters and a capacitor, the THD voltage has fallen dramatically from 17.1 percent to 0.6 percent with an impedance of 407 Likewise, from $7.4 \%$ to 0.3 percent, the new THD has decreased. The PF has risen from 0.3 to almost 0.9 , coming close to the ideal 1.0.0. The proposed technique is therefore highly effective. 1.

Table 1: Comparison between voltage $T H D_{v}$ and current $T H D_{i}$ before and after adding the capacitor with the aid of the filter

\begin{tabular}{|l|l|l|l|l|l|}
\hline$Z(\Omega)$ & $\begin{array}{l}\text { THD }_{\mathrm{v}} \\
\text { Without } \\
\text { Filter } \\
(\%)\end{array}$ & $\begin{array}{l}\mathrm{THD}_{\mathrm{i}} \\
\text { Without } \\
\text { Filter } \\
(\%)\end{array}$ & $\begin{array}{l}\text { Capacitor } \\
(\mathrm{F})\end{array}$ & $\begin{array}{l}\mathrm{THD}_{\mathrm{v}} \\
\text { with } \\
\text { Filter } \\
(\%)\end{array}$ & $\begin{array}{l}\mathrm{THD}_{\mathrm{i}} \\
\text { with } \\
\text { Filter } \\
(\%)\end{array}$ \\
\hline 407 & 17.1 & 7.4 & $6.2 \mathrm{E}-06$ & 0.6 & 0.3 \\
\hline 400 & 16.2 & 7.1 & $8.0 \mathrm{E}-06$ & 0.7 & 0.4 \\
\hline 301 & 17.0 & 7.8 & $9.3 \mathrm{E}-06$ & 0.71 & 0.4 \\
\hline 261 & 17.01 & 7.12 & $1.0 \mathrm{E}-05$ & 0.72 & 0.4 \\
\hline 224 & 17.04 & 7.11 & $1.1 \mathrm{E}-05$ & 0.69 & 0.5 \\
\hline 193 & 17.08 & 7.14 & $1.2 \mathrm{E}-05$ & 0.73 & 0.5 \\
\hline 169 & 18 & 7.51 & $1.2 \mathrm{E}-05$ & 0.8 & 0.7 \\
\hline 151 & 17.53 & 7.19 & $1.1 \mathrm{E}-05$ & 0.98 & 0.95 \\
\hline 338 & 17.98 & 7.18 & $8.4 \mathrm{E}-06$ & 0.02 & 0.1 \\
\hline 488 & 16.82 & 7.00 & $6.1 \mathrm{E}-06$ & 0.74 & 0.4 \\
\hline 319 & 16.80 & 7.20 & $9.5 \mathrm{E}-06$ & 0.7 & 0.4 \\
\hline 335 & 17 & 7.31 & $9.1 \mathrm{E}-06$ & 0.7 & 0.4 \\
\hline 242 & 17.01 & 7.08 & $1.1 \mathrm{E}-05$ & 0.7 & 0.4 \\
\hline 187 & 17.2 & 7.16 & $1.3 \mathrm{E}-05$ & 0.80 & 0.5 \\
\hline 279 & 17.52 & 7.3 & $1.0 \mathrm{E}-05$ & 0.8 & 0.4 \\
\hline 156 & 17.69 & 7.4 & $1.9 \mathrm{E}-05$ & 0.8 & 0.5 \\
\hline 138 & 17.03 & 7.5 & $1.39 \mathrm{E}-05$ & 0.9 & 0.51 \\
\hline 152 & 17.7 & 7.22 & $1.40 \mathrm{E}-05$ & 0.6 & 0.49 \\
\hline 131 & 18 & 7.20 & $1.41 \mathrm{E}-05$ & 0.7 & 0.71 \\
\hline
\end{tabular}

Table 2: Comparison between PF before and after adding the capacitor

\begin{tabular}{|l|l|l|l|}
\hline$Z(\Omega)$ & Distorted P.F & Capacitor $(\mathrm{F})$ & $\begin{array}{l}\text { Corrected } \\
\text { P.F }\end{array}$ \\
\hline 406 & 0.30 & $6.2 \mathrm{E}-06$ & 0.8 \\
\hline 359 & 0.34 & $8.0 \mathrm{E}-06$ & 0.91 \\
\hline 300 & 0.4 & $9.4 \mathrm{E}-06$ & 0.98 \\
\hline 260 & 0.47 & $1.0 \mathrm{E}-05$ & 0.99 \\
\hline 223 & 0.55 & $1.1 \mathrm{E}-05$ & 0.92 \\
\hline 192 & 0.64 & $1.2 \mathrm{E}-05$ & 0.94 \\
\hline 168 & 0.7 & $1.2 \mathrm{E}-05$ & 0.95 \\
\hline 150 & 0.82 & $1.1 \mathrm{E}-05$ & 0.95 \\
\hline 338 & 0.36 & $8.5 \mathrm{E}-06$ & 0.96 \\
\hline 487 & 0.25 & $6.1 \mathrm{E}-06$ & 0.97 \\
\hline 318 & 0.15 & $9.5 \mathrm{E}-06$ & 0.91 \\
\hline 334 & 0.14 & $9.1 \mathrm{E}-06$ & 0.99 \\
\hline 241 & 0.41 & $1.1 \mathrm{E}-05$ & 0.99 \\
\hline 186 & 0.53 & $1.4 \mathrm{E}-05$ & 0.98 \\
\hline 279 & 0.17 & $1.0 \mathrm{E}-05$ & 0.97 \\
\hline 156 & 0.32 & $1.9 \mathrm{E}-05$ & 0.95 \\
\hline 137 & 0.72 & $1.5 \mathrm{E}-05$ & 0.94 \\
\hline 152 & 0.65 & $1.5 \mathrm{E}-05$ & 0.99 \\
\hline
\end{tabular}




\section{Existing and future power quality system model for different loads}

In the current technological transition scenario, power is very precious. A lot of researches need to improve the power quality system and find out the causes of power loss. In industries the huge increase in the use of inductive loads will leads to deficiency of the power system hence a routinely techniques have been used to detect the failures of their loads and correct it[22]. The classical approach shown in Figure 7 is to connect a direct act device with a current transformer (C.T) across the industrial input power lines. The C.T is directly installed at each load. In the classical scenarios, the technique of switching method (on/off) is used. Each load is supported by a controller device which is responsible for detection or cancellation to any failure on each line.

For example, to correct the power factor, these old techniques make use of a microcontroller to control the switching phase of the linked capacitor bank at the end of the main power supply. Each load has its specific control device connected to the main power supply close to the variable load. The controller's job is to read the power factor, voltage and current of the device. Then the controller determines, according to a proven algorithm, to cut off the power for the specified load and decide how many capacitors should be added to raise the power factor to the value required.

With this classical approach, there are two major problems: (1) the correction is a fixed one, so that if the industrial load differs, the correction becomes either less efficient or on the other hand, potentially overly efficient, resulting in an undesirable low leading power factor , (2) many industrial capacitor banks have inherently unpredictable maintenance problems. It would therefore be highly desirable to provide a device that would automatically correct the power factor of an induction motor in real time, so that as the applied mechanical load is varied, the motor runs at or near optimum efficiency continuously.

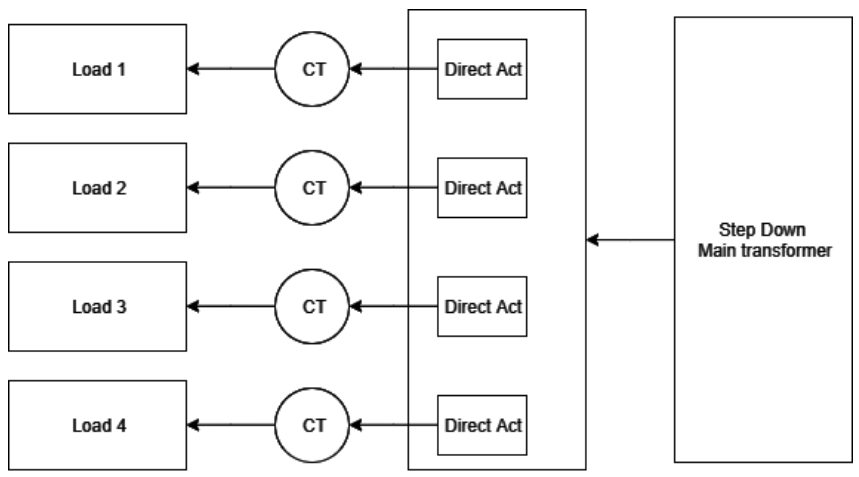

Figure 7: The classical power quality model for different load.

Substantial energy savings could be achieved through the Building Energy Management System (BEMS) within the Smart Electric Grid setting. A new technique based on IoT real time data acquisition using Message Queuing Telemetry Transport (MQTT) protocol which is the most commonly used protocols in IoT projects. The proposed architecture make use of real-time data to ensure prediction of machine failure using power quality data and ways to improve energy efficient process. The development of an energy monitoring system with the ability to acquire, process and store data in real-time is required for improving energy efficiency operations of the manufacturing industries and to enable proactive maintenance .This architecture prove the concept of sense, infer and act. As shown in Figure 8, the IoT beacons can contact with each other through the MQTT protocol. Thus, they can agree together that for example load number (2) will be compensated only. Consequently, tune tone generated by centralized harmonic cancellation to connect central node to a specific load.

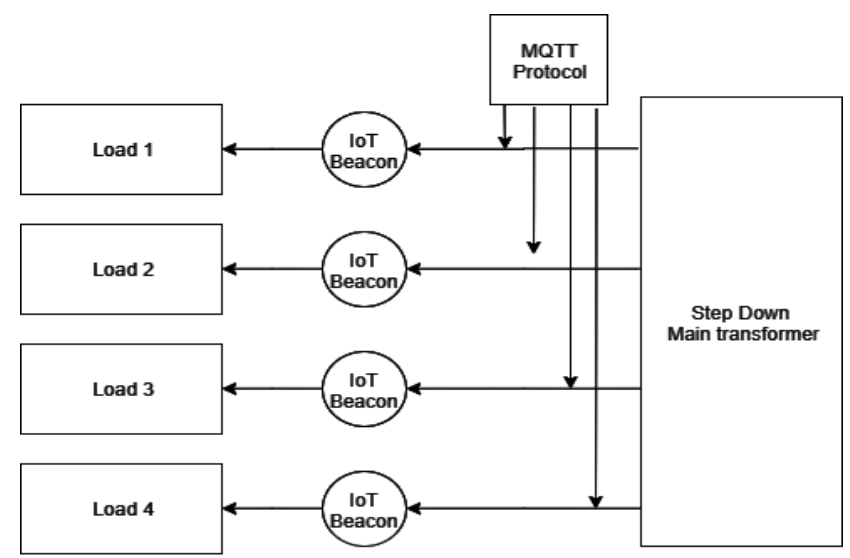

Figure 8: Future power quality system model for different loads.

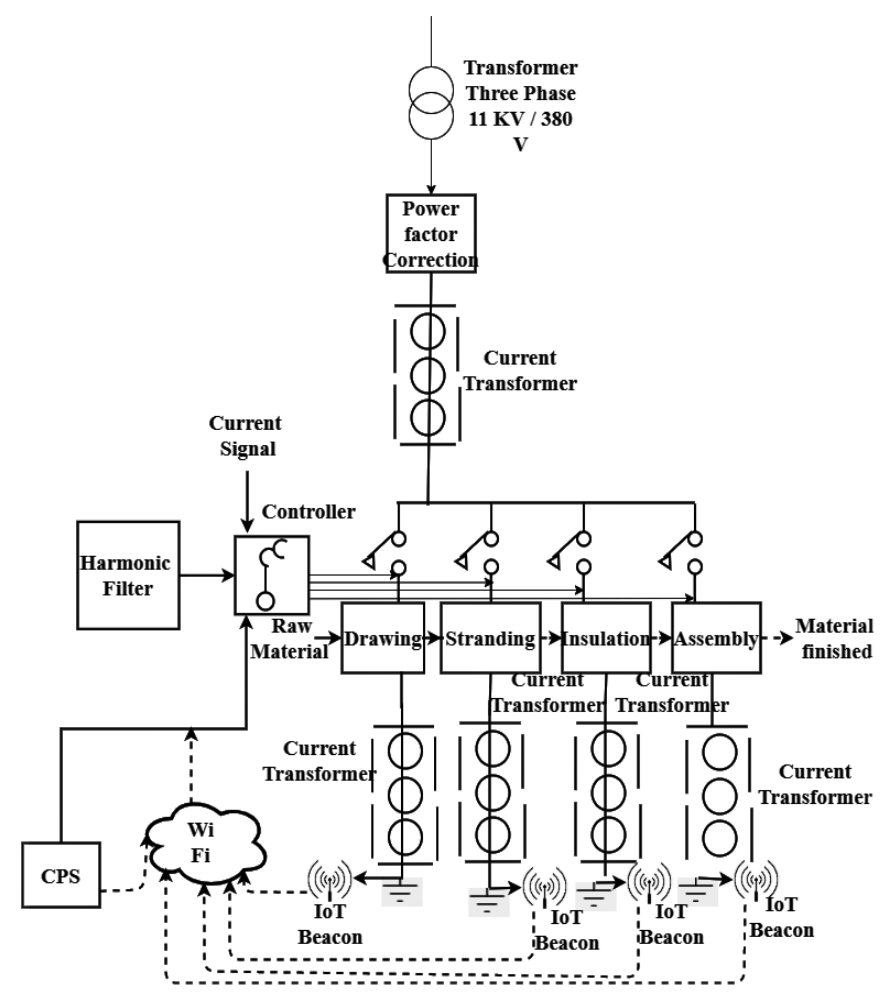

Figure 9: The proposed model for energy management technique.

6. Power factor and harmonics improvement: A Case study and Analysis of the processes of the production of a metals in Factories

This work is a case study and review of the technological and energy aspects of the recommended design of the metal factory production lines in Egypt. The study provide the factory with some technologies which can be integrated into the factory production 
processes in order to improve the product quality, minimize the need for electrical energy, reduce maintenance time and cost, and increase reliability and real-time data accuracy.

This study reviewed the production line of metals in factories. The metal production line consists of four main process illustrated in Figure 9 which are drawing, stranding, insulation and assembly. In this power quality assessment, a power quality analysis of metal production process has been shown where power is given to different loads through transformer. Readings of power quality parameters such as voltage unbalance, current unbalance, power factor, harmonics and voltage fluctuation in each phase of the metal production have been studied.

The purpose of the electrical distribution system is to support proper operation of the loads. When any one of the loads fails to meet its purpose, it is time to investigate the problem, find the cause and initiate corrective action. When a load does not operate properly, the other loads agree together through the proposed architecture shown in Fig.9 that this load should be compensated only. Figure 10-13 show the average voltage distortion, average current distortion, average power factor and average harmonic in the drawing phase, stranding phase, insulation phase and assembly phase respectively from the metal factory. Finally all these parameters are measured at the main line, so that the power factor and the harmonics at the main line can be fixed directly. Thus, Figure 14 and Figure 15 illustrated the reading at the main line before and after correction correspondingly.

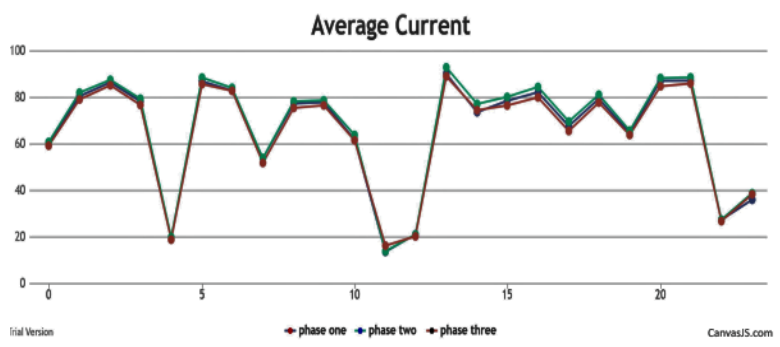

(a)

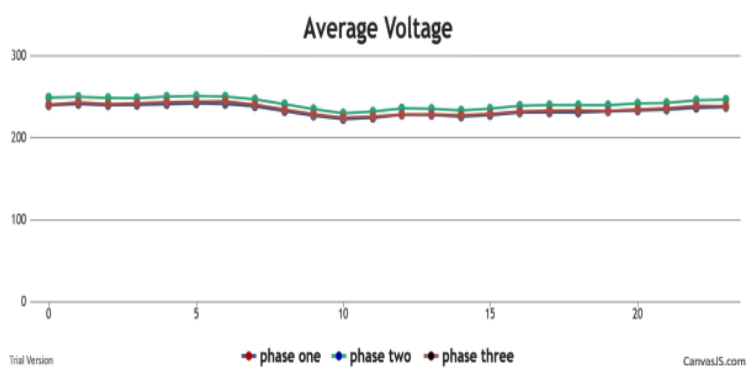

(b)

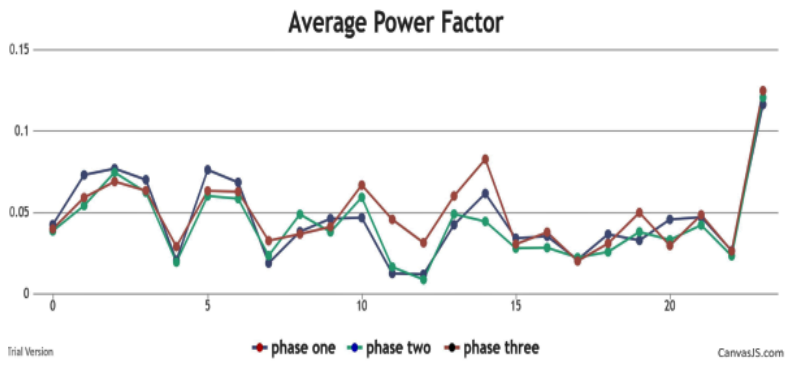

(c)

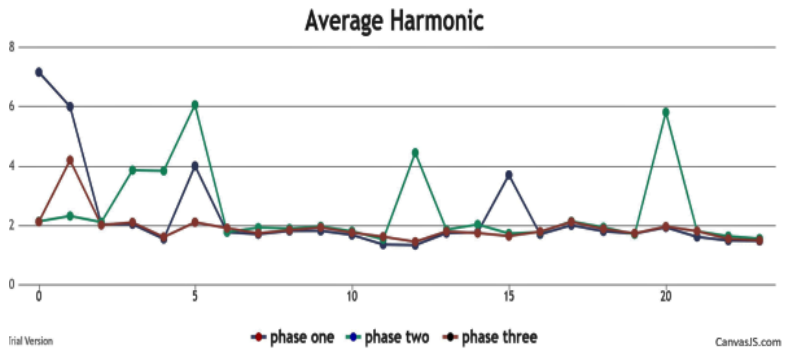

(d)

Figure 10: (a) The average current distortion, (b) average voltage distortion, (c) average power factor and (d) average harmonic in the drawing phase respectively.

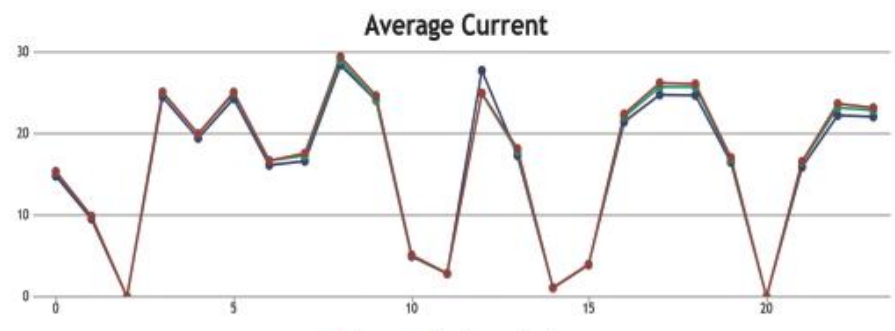

(a)

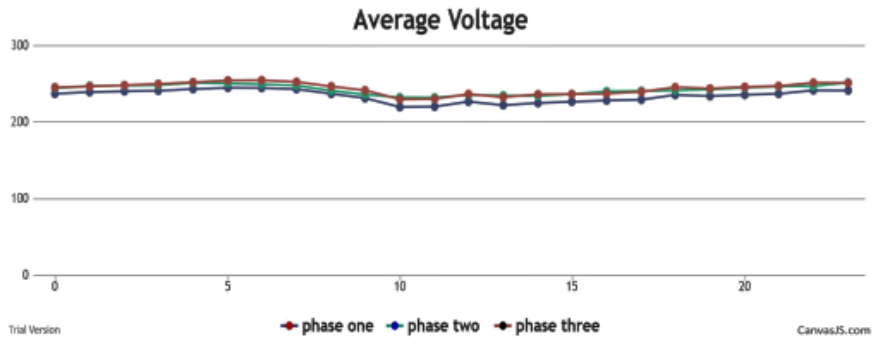

(b)

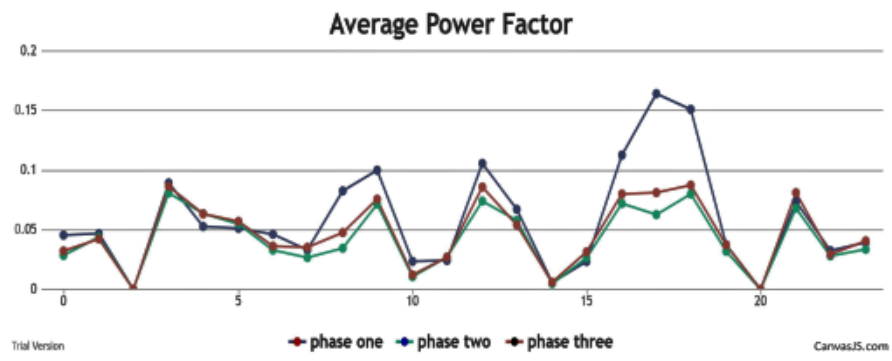

(c)

Average Harmonic

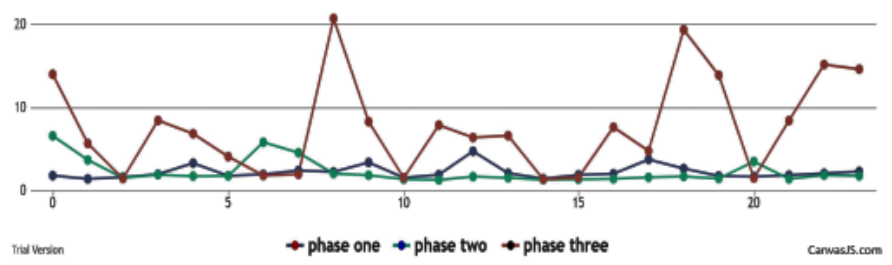

(d)

Figure 11: The average current distortion, average voltage distortion, average power factor and average harmonic in the Stranding phase respectively. 
Average Current

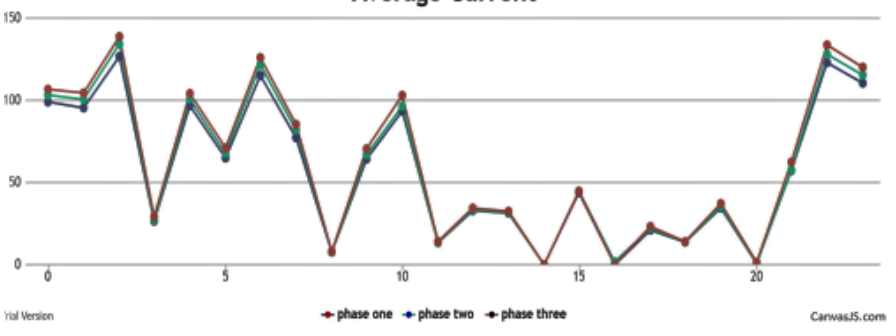

(a)

Average Voltage

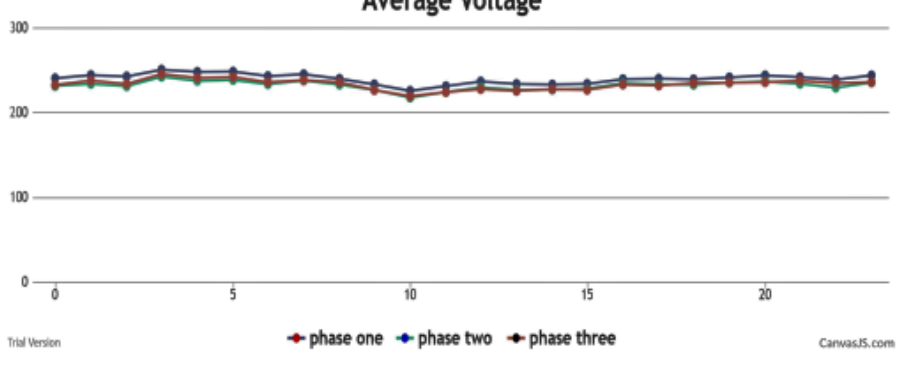

(b)

Average Power Factor

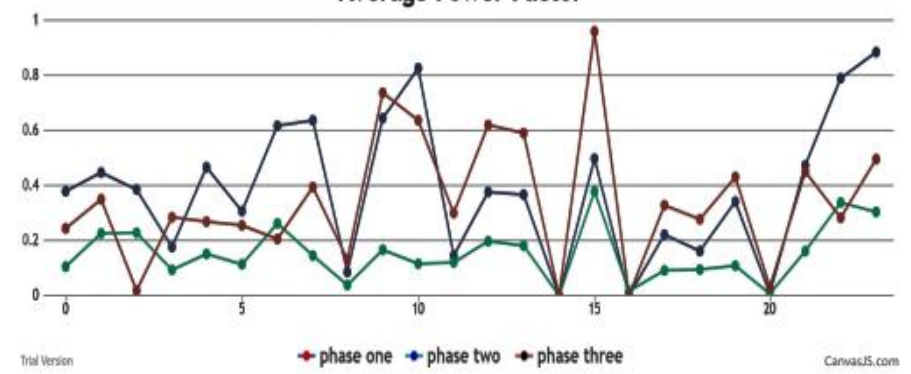

(c)

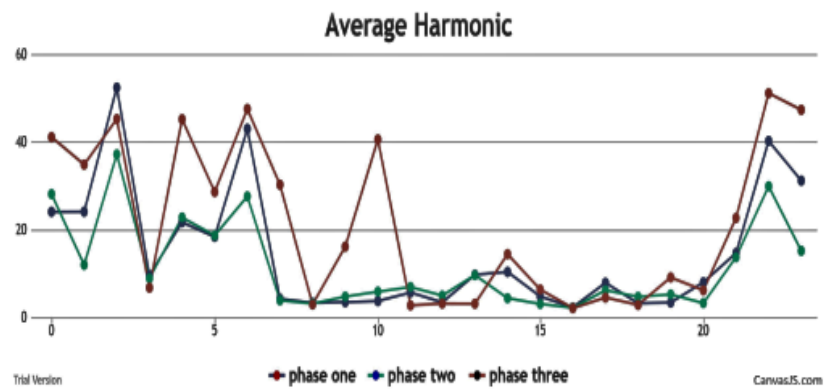

(d)

Figure 12: (a) The average current distortion, (b) average voltage distortion, (c) average power factor and (d) average harmonic in the insulation phase respectively.

Average Current

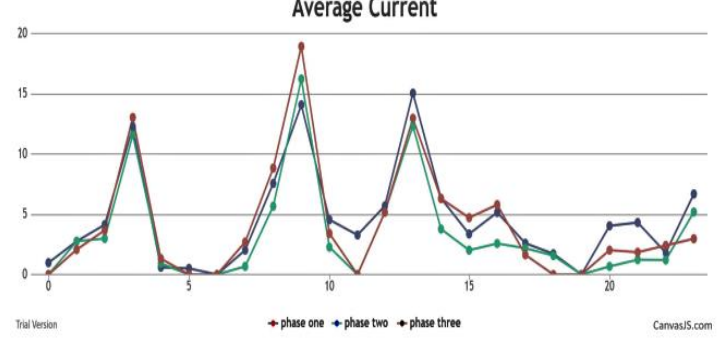

(a)

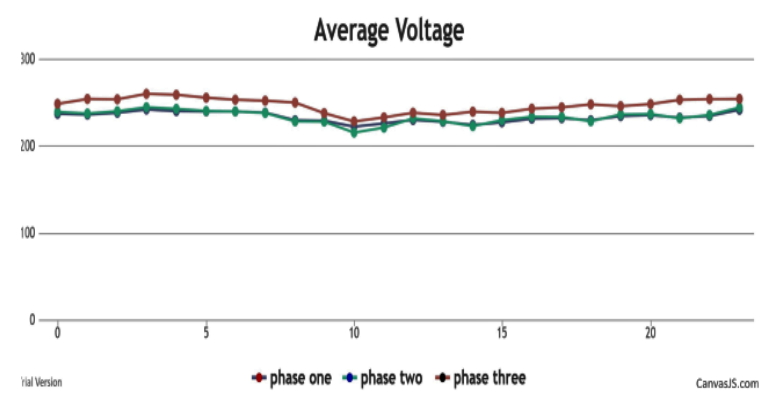

(b)

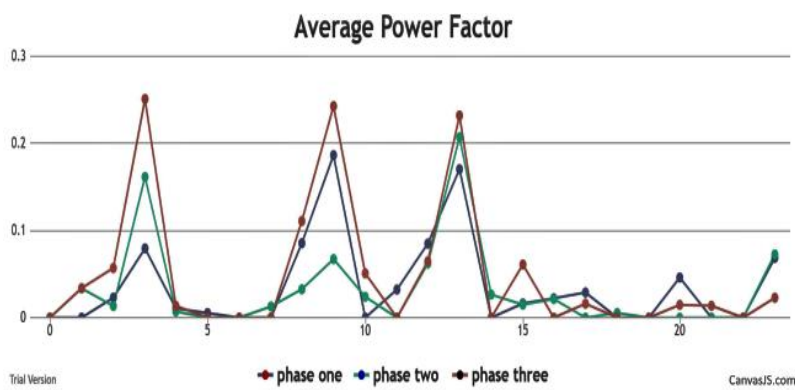

(c)

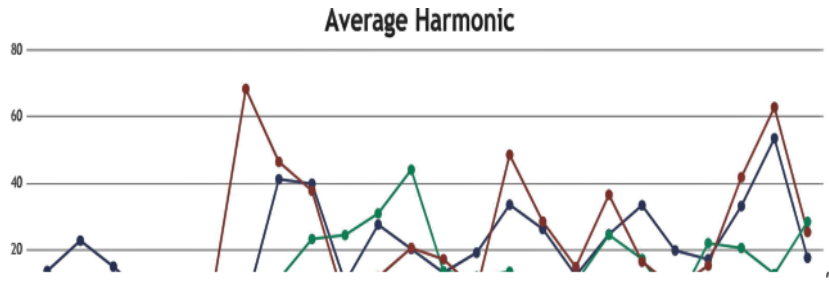

(d)

Figure 13: The Assembly phase (a) The average current distortion, (b) average voltage distortion, (c) average power factor and (d) average harmonic in the assembly phase. Average Current

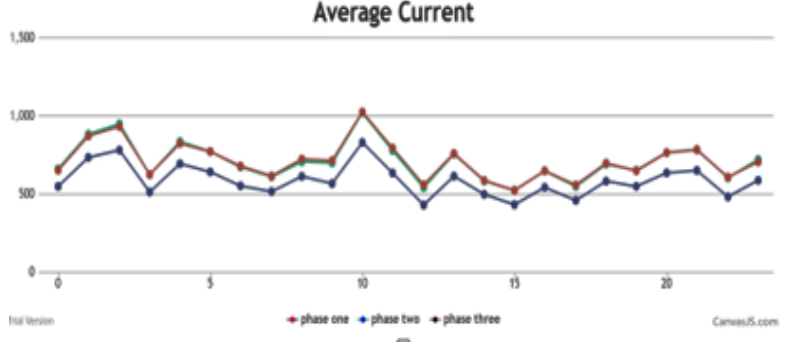

(a)

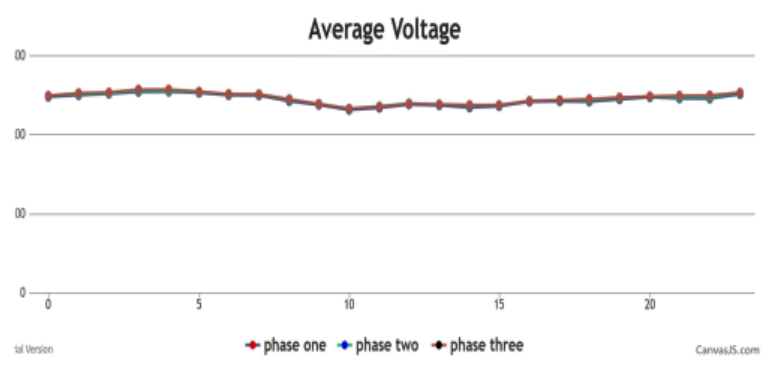

(b) 


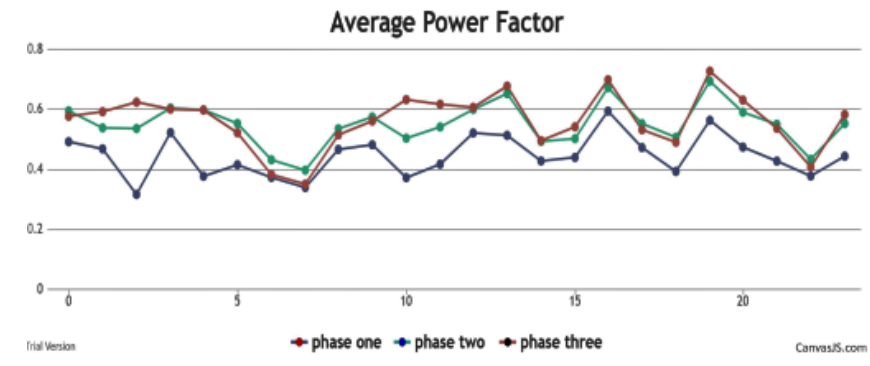

(c)

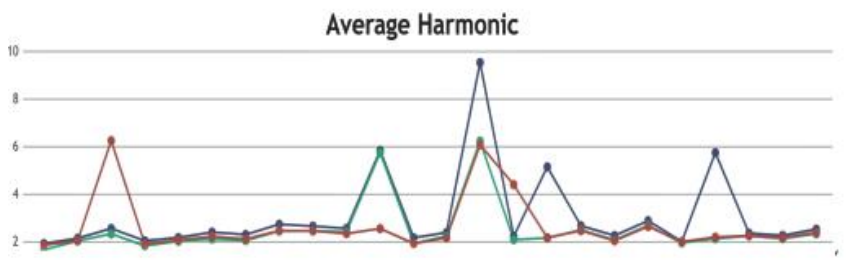

(d)

Figure 14: The average current distortion, average voltage distortion, average power factor and average harmonic readings respectively for the main line before correction.

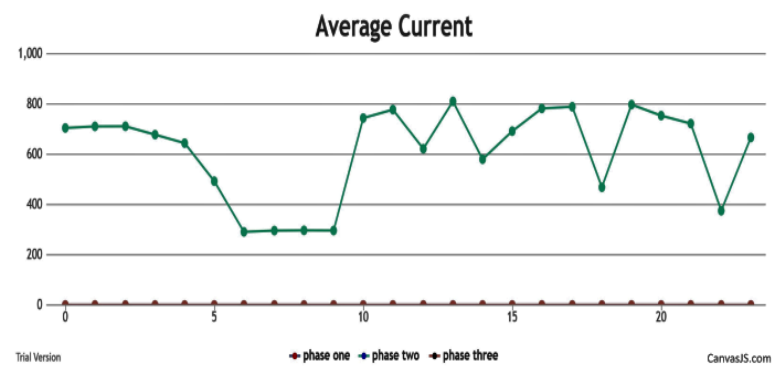

(a)

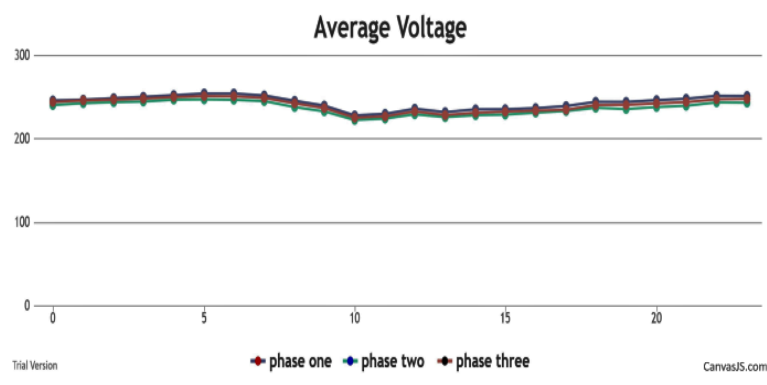

(b)
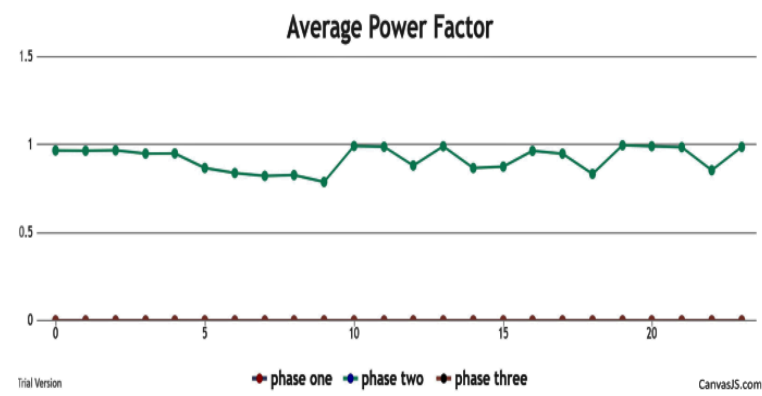

(c)

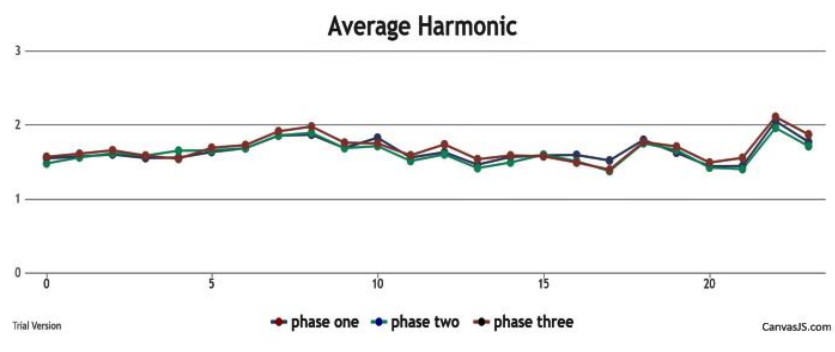

(d)

Figure 15: The average current distortion, average voltage distortion, average power factor and average harmonic readings respectively for the main line after correction.

The proposed system shown in Figure 9 will monitor the load current to detect the harmonics wave up to 49 th order and performs the computing process to analyse and calculate the power factor, then to transfer them to the high current capacity rectifier module along with the module processor in order to generate the compensation current in reverse direction, with overall response time less than $10 \mathrm{~ms}$ and perform exceeding $97 \%$.

Furthermore, Figure 16 illustrated the power consumption for one of the loads in four days. The measuring is taken by calculating the consumption of power for the three phases of one of the loads over time. Thus, it can be concluded that when using the proposed architecture a daily real time monitoring can be conducted which offers an understanding of energy usage and efficiency across different loads.

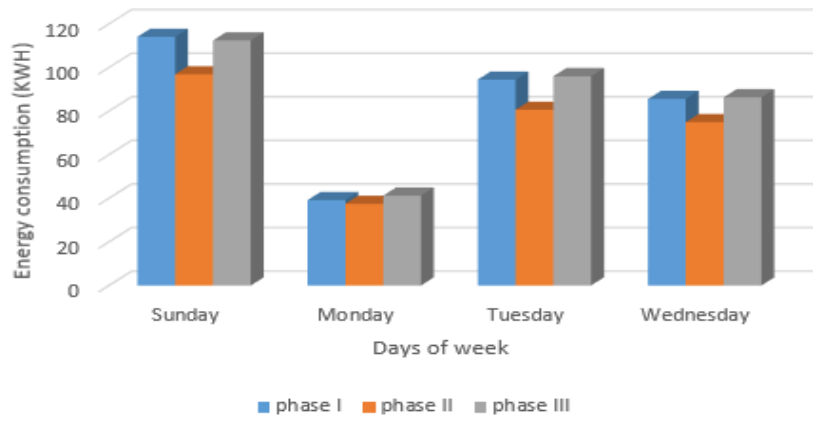

Figure 16: Energy consumption on one of the loads through four days

\section{Discussion and conclusion}

The manufacturing industry has been challenged with a lot of power quality problems in the overall including power factor, harmonics, unbalance ratios, power swells and dwells. Traditional techniques are moving towards correction steps as power factor correction using capacitor banks, synchronous power factor correction on individual loads, passive harmonic cancellations, active harmonic cancellations, soft switches to absorb spikes, voltage regulators, inverting technologies and others. However, those techniques are more focusing on correction of power rather than correction of manufacturing process that leads to the impact. 
In the presented work, energy-aware process control model is proposed that is depended on IoT technology that enables

the communication between PLC on machines and the energy management analytic platform on board to pinpoint the process

that causes the phenomena to happen rather than the machine.

example, if two different machines working in parallel and doing the same operation type, machine $x$ and machine $y$, that are

installed in a factory. If the two machines are operating during three time shifts daily. Once the proposed model explore

that

machine $x$ is doing wide spectrum of harmonic compared to

machine y. The model will operate machine y for only two

time shifts while machine $x$ will operate for only one time shift.

Hence the proposed model is able to stop the noisy machine and

improve

the overall power quality.

The model is simulated using MATLAB and is applied on a use case in factory that is specialized in cable industry. The results shows that the model pinpoints key areas of improvement of reducing the operation hours of a specific mal functioning

machine by one shift (eight hours) and increasing on the

other

side of operation hours of other two healthy machines doing

the same operation type by 3 hours each has led to significant improvement of the power factor by $33 \%$ to reaches

0.93

versus 0.7 without impacting average OEE of the operation. On the other hand, the current total harmonic distortion is improved 10 times from $31.4 \%$ to $3.1 \%$ as shown in Figure 17 and 18 respectively.

The proposed model enables the cost-effective process

management concept to achieve the same production results

better power quality and less energy consumption with minimum

addition of correction nodes.

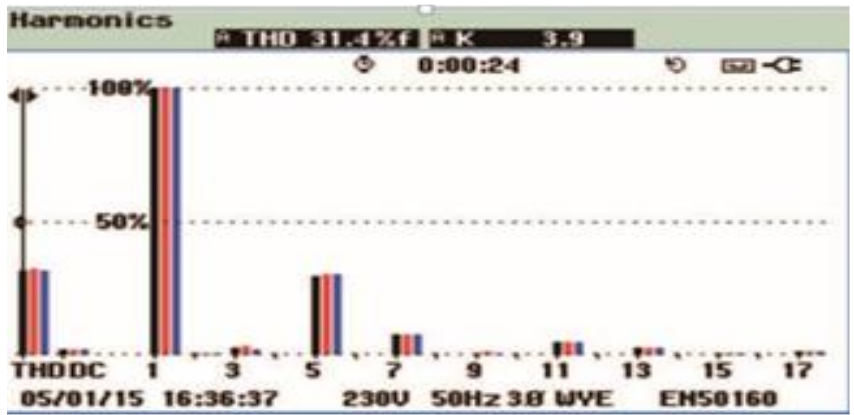

Figure 17: The Total Harmonic distortion (THD) before applying the proposed technique.

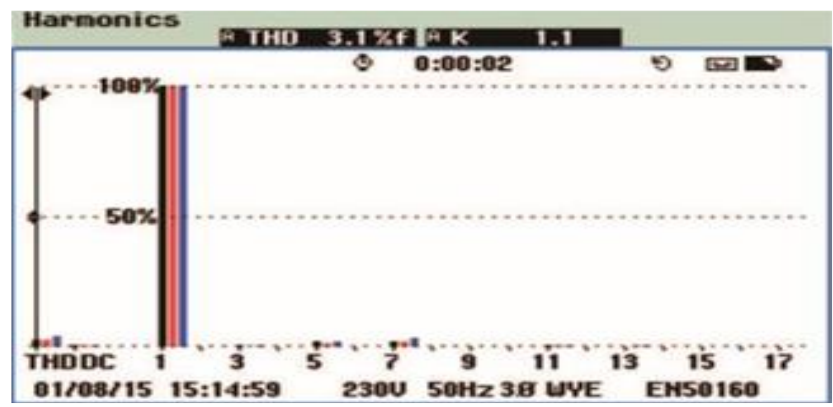

Figure 18: The Total Harmonic distortion (THD) after applying the proposed

\section{References} technique.

[1] N.N. Gomaa, K.Y. Youssef, M. Abouelatta, “An IoT-based energy efficien system for industrial sector," ICENCO 2019 - 2019 15th International Computer Engineering Conference: Utilizing Machine Intelligence for a Better World, 132-137, 2019, doi:10.1109/ICENCO48310.2019.9027440.

[2] V. Muni, R. Sangepu, "Effect of Power Quality Issues in Power System and Its Mitigation by Power Electronics Devices," Discovery, 28(105), 72-79, 2015.

[3] M. Krones, E. Müller, "An approach for reducing energy consumption in factories by providing suitable energy efficiency measures," Procedia CIRP, 17, 505-510, 2014, doi:10.1016/j.procir.2014.01.045.

[4] M.Z. Fortes, L.B. De Sousa, "Analysis of the Effects of Voltage Unbalance on Three-Phase Induction Motors," 3(2), 29-37, 2018, doi:10.1007/s12053015-.

[5] S. Rüstemli, E. Okuducu, M.N. Almalı, S.B. Efe, "Reducing the effects of harmonics on the electrical power systems with passive filters," Bitlis Eren University Journal of Science and Technology, 5(1), 1-10, 2015, doi:10.17678/beujst.57339.

[6] S. A, "Power Quality and Harmonic Analysis in Three Phase Systems," Journal of Electrical \& Electronic Systems, 7(4), 2018, doi:10.4172/23320796.1000291

[7] Z. Cao, Y.W. Chung, Y. Xiong, C.C. Chu, R. Gadh, "IoT based manufacturing system with a focus on energy efficiency," IEEE PES Innovative Smart Grid Technologies Conference Europe, 545-552, 2016 , doi:10.1109/ISGT-Asia.2016.7796443.

[8] R.O. Aburukba, A.R. Al-Ali, T. Landolsi, M. Rashid, R. Hassan, "IoT based energy management for residential area," 2016 IEEE International Conference on Consumer Electronics-Taiwan, ICCE-TW 2016, 2016 doi:10.1109/ICCE-TW.2016.7521035.

[9] J. Huang, Z. Jiang, "Power Quality Assessment of Different Load Categories," Energy Proceda, 141, 345-351, 2017, doi:10.1016/j.egypro.2017.11.041.

[10] D. Ogheneovo Johnson, "Issues of Power Quality in Electrical Systems," International Journal of Energy and Power Engineering, 5(4), 148, 2016, doi:10.11648/j.ijepe.20160504.12 
[11] M.J. Ghorbani, H. Mokhtari, "Impact of harmonics on power quality and losses in power distribution systems," International Journal of Electrical and Computer Engineering, 5(1), 166-174, 2015, doi:10.11591/ijece.v5i1.pp166-174.

[12] S.X. Duarte, N. Kagan, "A power-quality index to assess the impact of voltage harmonic distortions and unbalance to three-phase induction motors," IEEE Transactions on Power Delivery, 25(3), 1846-1854, 2010, doi:10.1109/TPWRD.2010.2044665.

[13] M. Mazadi, S.H. Hosseinian, W. Rosehart, D.T. Westwick, "Instantaneous voltage estimation for assessment and monitoring of flicker indices in power systems," IEEE Transactions on Power Delivery, 22(3), 1841-1846, 2007, doi:10.1109/TPWRD.2007.893188.

[14] Ö. Salor, B. Gültekin, S. Buhan, B. Boyrazoğlu, T. Inan, T. Atalik, A. Açik, A. Terciyanli, Ö. Ünsar, E. Altintaş, Y. Akkaya, E. Özdemirci, I. Çadirci, M. Ermiş, "Electrical power quality of iron and steel industry in Turkey," IEEE Transactions on Industry Applications, 46(1), 60-80, 2010, doi:10.1109/TIA.2009.2036547.

[15] R. M Patil, M.S. Nagaraj, P.S. Venkataramu, "Design and Implementation of Harmonic Trap Filter in Conjunction with a Line Reactor using Simulink," International Journal of Electrical and Electronics Engineering, 3(9), 7-16, 2016, doi:10.14445/23488379/ijeee-v3i9p102.

[16] A. Sharma, "Dependence of Power Factor on Inductive Loads for Microcontroller based Power Systems," IOSR Journal of Electrical and Electronics Engineering, 7(2), 30-35, 2013, doi:10.9790/1676-0723035.

[17] P. Papechen, S. Sebastian, "Automatic Power Factor Correction Using Capacitor Banks," International Journal of Innovative Research in Electrical, Electronics, Instrumentation and Control Engineering, 4(7), 2321-2004, 2016, doi:10.17148/IJIREEICE

[18] J.D.M. Mohamed Ibrahim A1 , Karthikeyan A2, Aravind K3, Gokulakrishna S4, "Minimizing Industrial Power Consumption Penalty By Using Thyristor Switching Capacitor," International Journal of Recent Trends in Engineering and Research, 4(3), 741-749, 2018, doi:10.23883/ijrter.2018.4192.qidou.

[19] A.H. Bagdadee, L. Zhang, "A Review of the Smart Grid Concept for Electrical Power System," International Journal of Energy Optimization and Engineering, 8(4), 105-126, 2019, doi:10.4018/ijeoe.2019100105.

[20] J.S. Vardakas, N. Zorba, C. V. Verikoukis, "A Survey on Demand Response Programs in Smart Grids: Pricing Methods and Optimization Algorithms," IEEE Communications Surveys and Tutorials, 17(1), 152-178, 2015, doi:10.1109/COMST.2014.2341586.

[21] M.C.L. Padilla syamala, "An IOT Based Appliances Control for Smart Homes," in 2013 Fourth International Conference on Intelligent Control and Information Processing (ICICIP), 170-174, 2017, doi:10.1109/ICICIP.2013.6568171.

[22] M.I. Muhamad, N. Mariun, M.A.M. Radzi, "The effects of power quality to the industries," 2007 th Student Conference on Research and Development, SCORED, (January), 2007, doi:10.1109/SCORED.2007.4451410. 